\title{
Characteristics and origin of a new type of polyhalite potassium ore in the Lower Triassic Jialingjiang Formation, Puguang area, northeastern Sichuan Basin, SW China
}

Wen-Jun Shang ${ }^{1,2}$, Mian-Ping Zheng ${ }^{1,2}$, Yong-Sheng Zhang ${ }^{1,2,3}$, Jia-Ai Zhong ${ }^{1,2^{*}}$, En-Yuan Xing ${ }^{1,2}$, Yuan Peng ${ }^{1,2}$, Bao-Ling Gui ${ }^{1,2}$ and Kong Li ${ }^{4}$

\begin{abstract}
A new type of polyhalite potassium ore (NTPPO) was found in the Lower Triassic Jialingjiang Formation, NE Sichuan Basin, SW China. It is water soluble, therefore can be exploited using the water-solution method, and is of great potential of economic value and research significance. Based on cores, thin sections, energy spectrum and SEM analyses, its microfeatures, macrofeatures and origin are discussed, and a genetic model is established to provide a scientific basis for future evaluation, prediction and exploration of potassium ore in the Sichuan Basin. It is proposed that the NTPPO was caused by storm activities: (1) the storm broke the original sedimentary polyhalite-gypsum beds, whose fragments were transported into the salt basin with high content of $\mathrm{K}^{+}$and $\mathrm{Mg}^{2+}$; (2) in the basin, the polyhalite continued to be formed from gypsum by metasomatism with $\mathrm{K}$ - and Mg-rich brine; (3) during diagenesis, under high temperature and high pressure, $\mathrm{K}-\mathrm{Mg}$-rich brine from halite continued to replace anhydrite (or gypsum) to form polyhalite.
\end{abstract}

Keywords: Puguang area, Lower Triassic, New type of polyhalite potassium ore, Microfeatures and macrofeatures, Storm event deposition

\section{Introduction}

Polyhalite is used as a high-quality soil-friendly chlorinefree fertilizer, which is rich in potassium and magnesium, and therefore is good for growing crops (Chen 1999; Zheng et al. 2018). Polyhalite has been found in the Sichuan Basin, Lop Nur, Qaidam Basin, Bohai Bay Basin and Jianghan Basin in China (Wang 1982; Zhao et al. 1987; Lin and Yin 1998; Liu et al. 2008, 2015; Niu et al. 2015). Among them, the polyhalite from the Triassic in the Sichuan Basin exhibits the widest distribution and the highest degree of enrichment, with a

\footnotetext{
*Correspondence: zhongja555@163.com

'Institute of Mineral Resources, Chinese Academy of Geosciences, Beijing 100037, China

${ }^{2}$ Key Laboratory of Salt Lake Resources and Environment, Ministry of Natural Resources, Beijing 100037, China

Full list of author information is available at the end of the article
}

potential reserve as much as 10 billion tons of $\mathrm{K}_{2} \mathrm{O}$ (Jin 1989). However, the polyhalite found in earlier periods mostly occur as layers or lenses in gypsum or anhydrite strata (Huang 1996), which is of relatively high mining cost due to poor water solubility (An et al. 2004); moreover, its economic value decreases to zero with increasing burial depth. So far, only the polyhalite from shallow strata in the Nongle area, Quxian county, Sichuan Basin, SW China, has been exploited (Huang 1996; Lin and Yin 1998), while those polyhalites in other areas, moderately to deeply buried, mostly remain unminable. Recently, our team found a large amount of clastic polyhalite, which is distributed in the thick halite of the Lower Triassic Jialingjiang Formation in the Puguang area, Xuanhan county, northeastern Sichuan Province, SW China. High solubility of the halite makes this polyhalite 
easy to be exploited via the water-solution method, which greatly reduces its mining cost; therefore, this deposit has great potential economic value. This polyhalite is considered as a new type of polyhalite potassium ore (hereinafter called the 'NTPPO', Zheng et al. 2018). This paper mainly focuses on microfeatures and macrofeatures of the NTPPO and analyzes its genesis in order to provide a scientific basis for future prospecting, prediction and evaluation of polyhalite in the Sichuan Basin.

The results of evaporation experiments (Han et al. 1982) show that polyhalite can be directly formed when the six-element system involving $\mathrm{K}^{+}, \mathrm{Na}^{+}, \mathrm{Mg}^{2+}, \mathrm{Ca}^{2+}$ / $\mathrm{Cl}^{-}, \mathrm{SO}_{4}{ }^{2-}$ and $\mathrm{H}_{2} \mathrm{O}$ reaches a certain equilibrium, or can be metasomatically formed by contact between a concentrated brine with high $\mathrm{K}^{+}$and $\mathrm{Mg}^{2+}$ concentrations and calcium sulfate salts, such as gypsum or anhydrite (Freyer and Voigt 2003; Wollmann et al. 2008, 2009; Wollmann 2010). The first type is called the primary sedimentary polyhalite, and the second is called the metasomatic polyhalite. The latter is further divided into: (1) parasyngenetic metasomatic polyhalite, that is, in the late stage of evaporation, polyhalite forms through reaction between concentrated brine with high $\mathrm{K}^{+}$and $\mathrm{Mg}^{2+}$ concentrations and previously precipitated calcium sulfate salts (such as gypsum and sodium sulfate) (Yuan 1974); and (2) postdiagenetic metasomatic polyhalite, formed by metasomatism of potassium- and magnesium-rich brine transported through structural cracks into contact with calcium sulfate salts, such as gypsum or anhydrite (Yuan 1974; Liao et al. 1984).

Based on laboratory studies, Chinese researchers have proposed the following views on the genesis of polyhalites deposited in anhydrite in the Sichuan Basin: (1) Primary deposition, in which polyhalite is formed by evaporation of a fluid mixture composed of $\mathrm{Ca}^{2+}$ - and $\mathrm{SO}_{4}{ }^{2-}$-rich drainage water from the gypsum succession and $\mathrm{K}^{+}$- and $\mathrm{Mg}^{2+}$-rich residual concentrated brine (Huang 1996). (2) Penecontemporaneous metasomatism, in which, during the process of deposition, the concentrated residual $\mathrm{K}^{+}$- and $\mathrm{Mg}^{2+}$-rich brine reacts with gypsum to form polyhalite (Huang 1996). (3) Metasomatism, in which during diagenesis $\mathrm{K}-\mathrm{Mg}$-rich brine from leaching of a salt layer ( $\mathrm{Li}$ and Han 1987; Pan 1988) or from an external hydrothermal environment reacts with gypsum or anhydrite to form polyhalite. Additionally, in the Lop Nur Salt Lake, Xinjiang Uygur Autonomous Region, NW China, Liu et al. (2008) suggested that there are two kinds of polyhalite precipitation mechanisms: (1) hydrothermal events, which might result in polyhalite precipitation through replacement of glauberite, or even direct precipitation from brine; (2) during the playa stage, $\mathrm{K}^{+}$- and $\mathrm{Mg}^{2+}$-rich intercrystal brine mixes with $\mathrm{Ca}^{2+}$-rich surface water, and precipitates polyhalite inter-halite crystals. Zhao et al. (1987) inferred that the late Eocene-Oligocene polyhalite in the Dawenkou Depression, Bohai Bay Basin, was precipitated from a mixture of a $\mathrm{Ca}^{2+}$-rich fluid surrounding the playa and a $\mathrm{K}^{+}$- and $\mathrm{Mg}^{2+}$-rich brine in the playa. Based on polyhalite characteristics in the Jianghan Basin, Wang (1982) summarized the genetic mechanism as follows: when a brine becomes sufficiently concentrated to deposit potassium and magnesium salts, the calcium ions transported by relatively low-salinity water combining with the potassium and magnesium in brine can result in formation of polyhalite. Niu et al. (2015) suggested that formation of polyhalite in the Bieletan area of the Qarhan Salt Lake, Qinghai, occurred through metasomatic replacement of early-formed salts by magnesium sulfates in lacustrine facies. Liu et al. (2015) proposed two genetic models for the polyhalite in Kunty Salt Lake, northwestern Qaidam Basin: the reaction between highly-concentrated brine and anhydrite; and the reaction between highly concentrated brine and $\mathrm{K}^{+}$-rich clay.

\section{Geological setting}

\subsection{Tectonic background}

The NTPPO was discovered in the Puguang area of Xuanhan county, northeastern Sichuan (Fig. 1a) in marine evaporative strata of the Jialingiiang Formation, topmost Lower Triassic (Fig. 2). This area is located in a highly elevated and steep tectonic belt, which has been superimposed and reconstructed by several phases of tectonic activity, resulting in very complex structures (Tang et al. 2008). Reverse faults in NW and NE directions are best developed (Fig. 1b). The gypsum salt layer in the Lower Triassic Jialingjiang Formation and Middle Triassic Leikoupo Formation experienced plastic deformation due to tectonic activities, forming a slippage zone; and its upper and lower strata show significantly different structural characteristics (Fig. 1c) (Zhou et al. 2013).

\subsection{Salt-forming background}

The largest extinction event in the Phanerozoic Eon occurred at the Permian-Triassic boundary (Raup 1979; Erwin 1994; Mundil et al. 2004; Alroy et al. 2008; Ogg and Gradstein 2008; Yin and Song 2013), when more than $90 \%$ of marine species disappeared, damaging marine and terrestrial ecosystems (e. g., Retallack 1995; Payne et al. 2006; Algeo et al. 2011). This was followed by a dramatic change in the global palaeoenvironment and palaeoclimate (Stanley 1988). The Early Triassic temperature increased (Sun et al. 2012), and large-scale monsoon systems developed (Parrish 1993). At this time, the Sichuan Basin was within the influence range of lowlatitude monsoons, which is between latitudes of $12.5^{\circ} \mathrm{N}$ and $15^{\circ} \mathrm{N}$ (Jiang et al. 1987; Zhu et al. 1988), subjected to hot and arid climates (Qian et al. 2010). During the Jialingjiang stage, the Sichuan Basin changed from an 

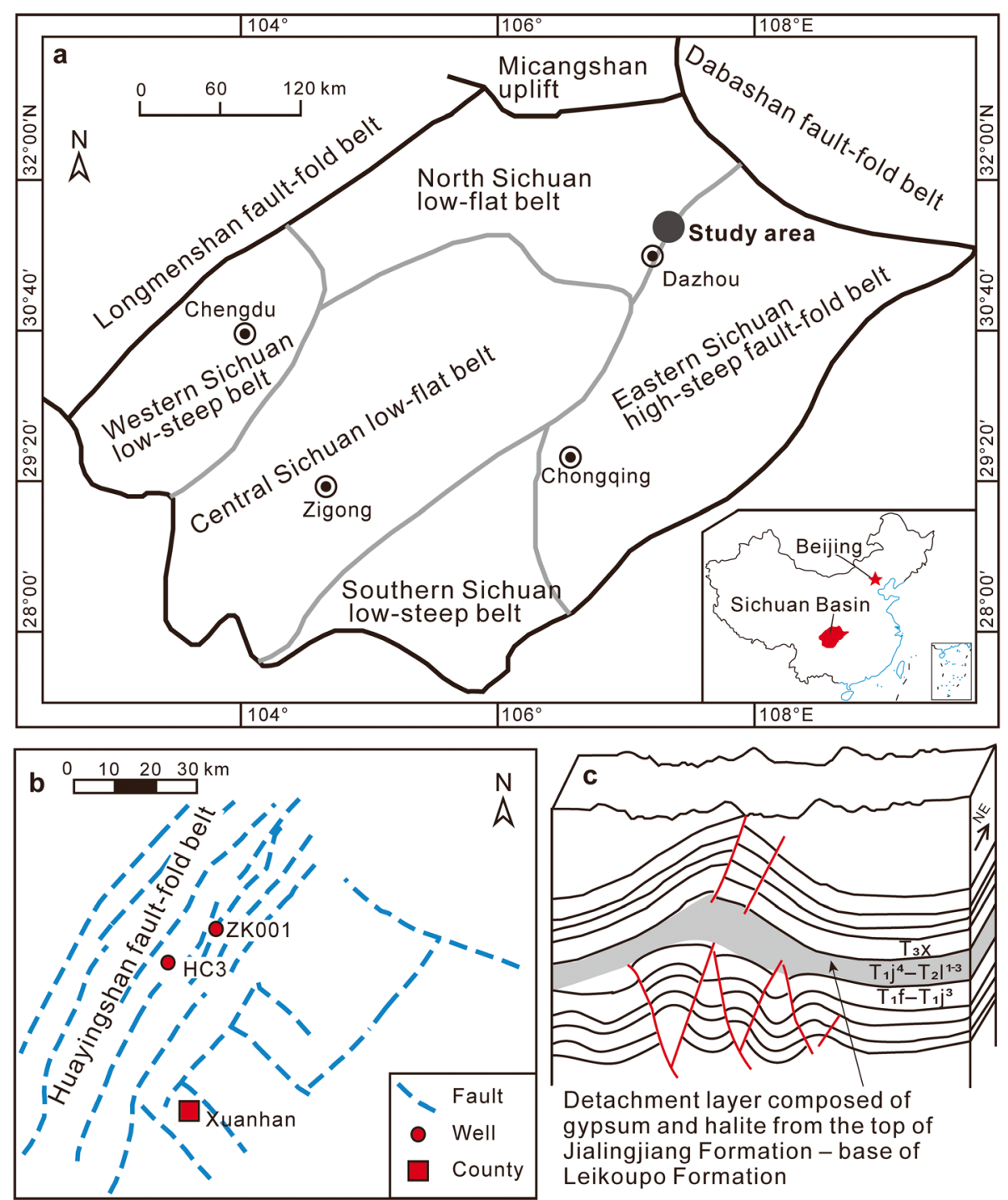

Fig. 1 a Map showing geographic position of the study area in Sichuan Basin, southwestern China. Black thick solid lines outline the Sichuan Basin; gray thick solid lines are boundaries of tectonic units of the Sichuan Basin (modified from Zhang et al. 2018). The inset map of China is modified after the Standard Map Service of the National Administration of Surveying, Mapping and Geoinformation of China (http://bzdt.ch.mnr. gov.cn/) (No. GS(2016)1603). b Basement faults and wells in the northeastern Sichuan Basin (modified from Tang et al. 2008). c Schematic crosssection showing evolution mode of the Puguang area (modified from An et al. 2009). For information on the members $T_{1} f_{1}, T_{1} j^{3}, T_{1}{ }^{4}, T_{2} l^{1-3}, T_{3} X_{1}$ see Fig. 2

open shelf to a limited basin as mountains rose around its periphery. The basin water was concentrated under evaporating conditions, forming a succession composed of marine carbonates (mainly dolomite) and gypsum (Fig. 1a), which covered an area of approximately $1.8 \times$ $10^{5} \mathrm{~km}^{2}$ (Zheng et al. 2010). Polyhalite is widely distributed in this area. During the late Jialingjiang stage, influenced by a sea-level fall, the marine environment of the peripheral palaeo-uplifts in Xuanhan county, mainly the Luzhou-Kaijiang Palaeohigh (e.g. $\mathrm{Xu}$ and Zhao 2003; Zhao et al. 2015), became highly restricted and changed from an open sea to a platform, on which large evaporitic basins developed (Chen et al. 2015; Zhao et al. 2015).

\section{Samples and methods}

The NTPPO is characterized by uneven distribution of polyhalite fragments in halite. The fragments are often of different sizes and complex shapes and occur in forms of fine grains, irregular blocks and strips that have been deformed or warped (Fig. 3a; Zheng et al. 2018). In the black halite, some slightly-wrinkled 2-4-cm-thick anhydrite layers have been found locally, in which halitedissolution holes were formed, indicating that they used 


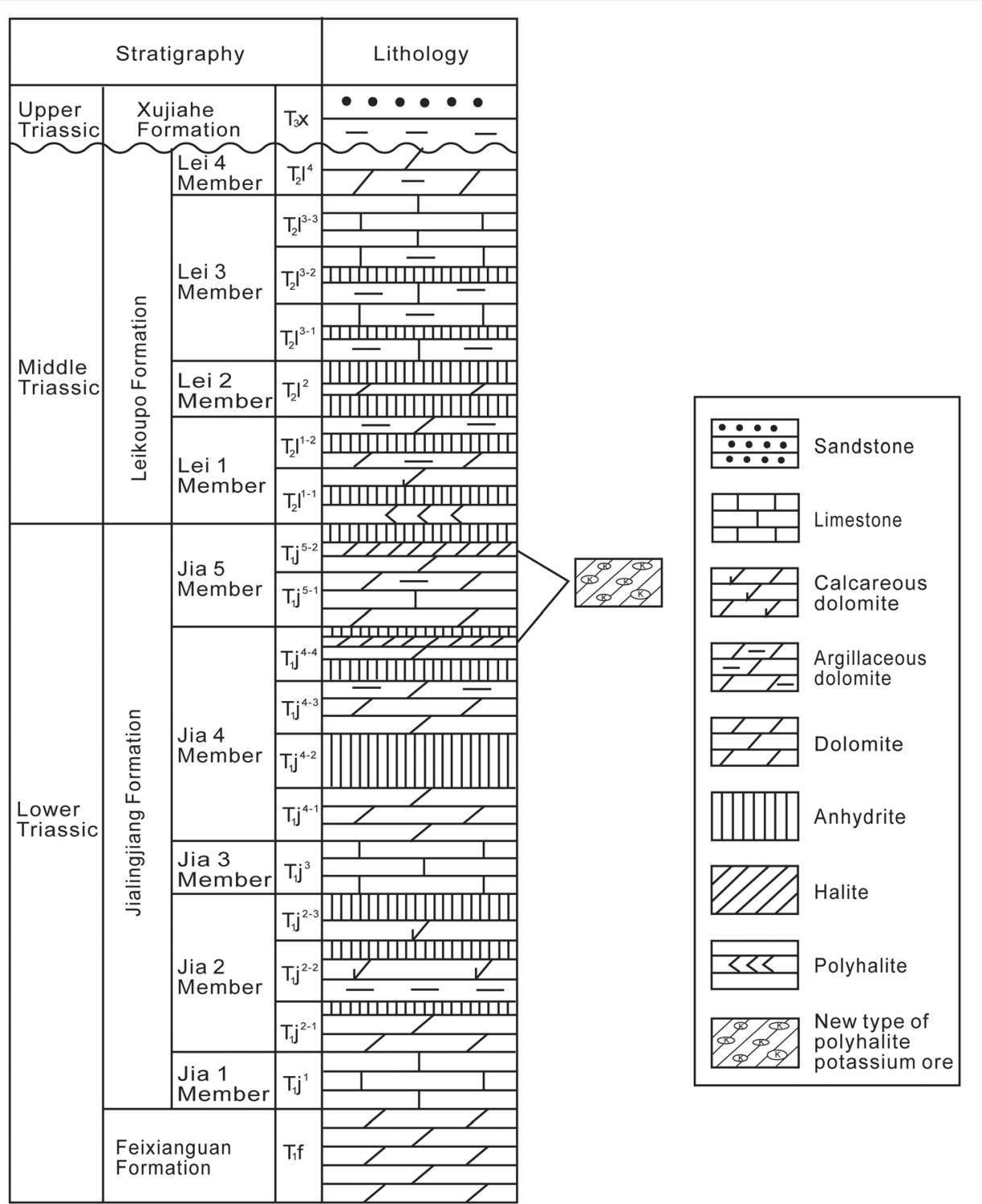

Fig. 2 Stratigraphy and lithology of the Lower-Middle Triassic in the northeastern Sichuan Basin (modified from Chen et al. 2010)

to contain halite crystals (Fig. 3a). The anhydrite layer at the bottom of NTPPO contains polyhalite blocks and interlayers (Fig. 3a). In this paper, according to different characteristics of the NTPPO, including the color of the halite matrix, and the size and shape of polyhalite fragments and their distribution characteristics in the halite matrix, 155 samples from two wells were selected for detailed analysis of lithological characteristics. By hand-specimen observation, thin-section analysis, scanning electron microscopy (SEM), and Xray diffraction, the deposition period and its origin were assessed.

Thin sections were observed under a LEICA2500P microscope. Carbon-covered thin sections were also examined under a Zeiss ultraplus scanning electron microscope at the Institute of Mineral Resources, Chinese Academy of Geological Sciences. The analytical conditions were as follows: acceleration voltage: $15 \mathrm{kV}$; image magnification: $\times 12-\times 1,000,000$ (secondary electron image) and $\times 100-\times 1,000,000$ (backscattered electron image). Samples were analyzed on a Rigaku D/ max-rA diffractometer using $\mathrm{Cu} \mathrm{K \alpha}$-radiation $(40 \mathrm{kV}$, $100 \mathrm{~mA}$ ). The measurements were performed in the step-scan mode with an angular range of $3^{\circ}-70^{\circ}$ at $1.5406 \AA$, with a step interval of $0.02^{\circ}$ and a rate of $8^{\circ} \%$ min at the Beijing Beida Yanyuan Microstructure Analysis and Testing Center Co., Ltd. The program EVA 3.0 (Bruker AXS) and the pdf-2-database (International Center for Diffraction Data) were used for evaluation of the X-ray diffraction results. 


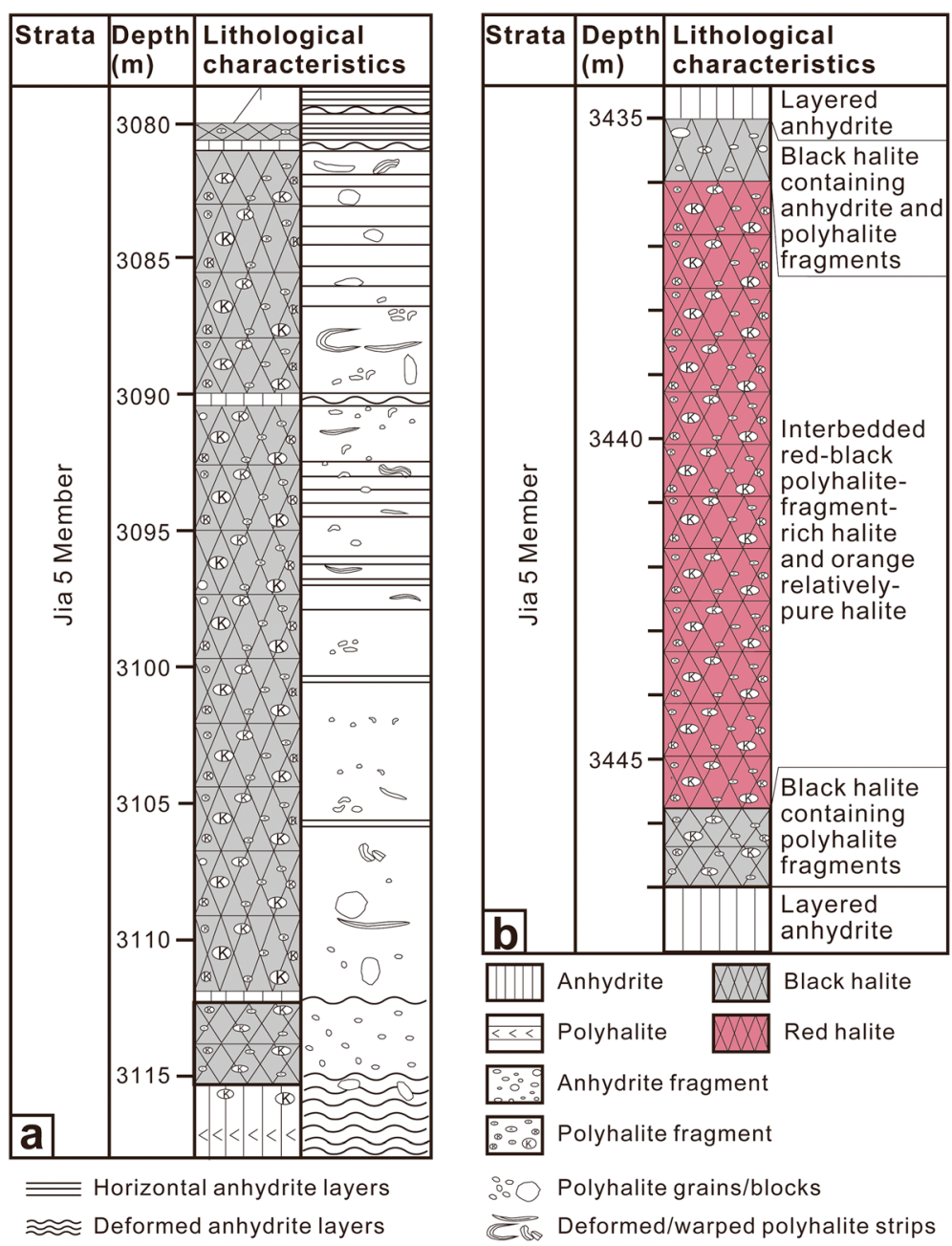

Fig. 3 Lithological characteristics of the new type of polyhalite potassium ore deposit in the wells ZKO01 (a) and HC3 (b). In a, irregular, differentsized polyhalite fragments (grains, blocks, and strips) are sketched according to core observation

\section{Results}

The NTPPO is mainly composed of a halite matrix and polyhalite fragments. In addition, small amounts of anhydrite, magnesite and clay are found in the polyhalite fragments.

\subsection{Halite matrix}

There are two kinds of halite matrix. (1) The black halite matrix is composed of white, gray, or black halite crystals, which are small, highly fragmented, and subhedral to euhedral. The relatively pure white or gray halite crystals contain less impurities than the black ones. Large halite crystals, which may be recrystallized, are locally present (Fig. 4a). (2) The red halite matrix is composed of red halite crystals, whose sizes are more uniform than those in the black halite matrix, mostly $0.3-0.8 \mathrm{~cm}$. The crystals are relatively euhedral, with their boundaries well-defined (Fig. 4b). It is generally believed that organic matter gives the sediments a black or light gray color, while high-valent iron oxide is the main cause for the red color. There is a good correlation between the generation and degree in iron enrichment and the average annual temperature. The redder sediments indicate a higher temperature and a higher degree of oxidation (Ding et al. 1964; Zhou et al. 1990; Li et al. 2006). Therefore, black halite was formed at the edge of the salt basin and experienced multiple rounds of seawater recharge, environmental turbulence and high organic matter input. In contrast, red halite formed far away from the provenance, in a relatively stable sedimentary environment. Brine temperature increased continuously during the evaporative conditions, resulting in a water body rich in high-valent iron oxide, which produced the red-colored halite (Fig. 3).

\subsection{Distribution of polyhalite in halite}

Polyhalite fragments occur as fine grains, irregular lumps and beds in the halite matrix. Their characteristics differ obviously in different kinds of halite matrix. (1) In the 


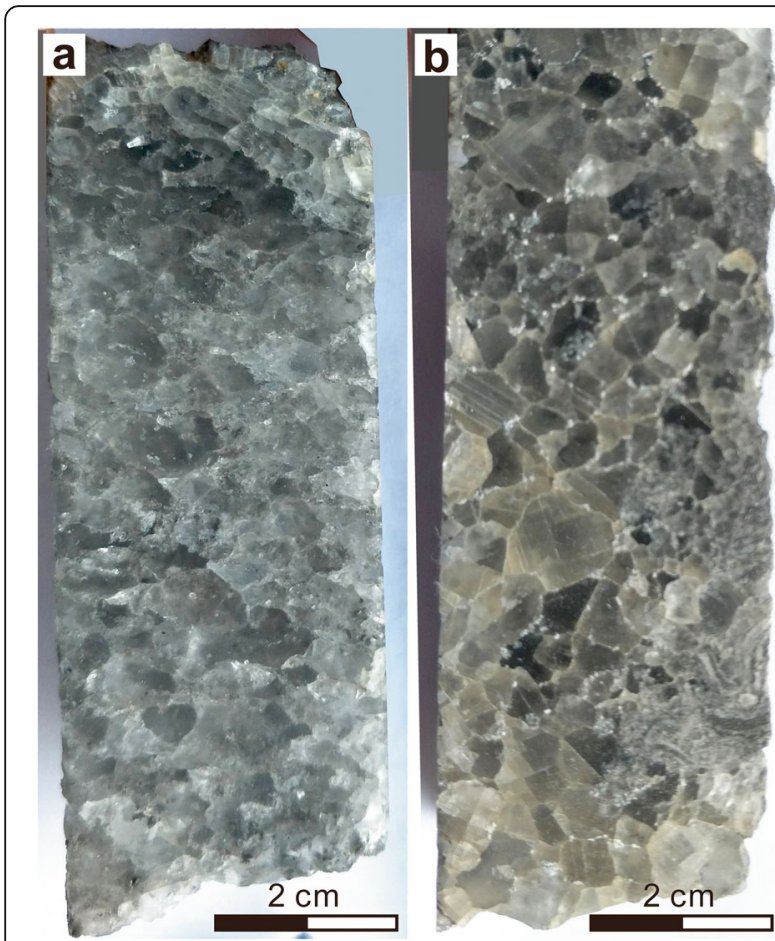

Fig. 4 Characteristics of the two kinds of halite matrix in polished core samples from the Well HC3. a Black halite matrix composed of fragmented crystals; $\mathbf{b}$ Red halite matrix composed of cube-shaped crystals

black halite, the size of polyhalite fragments varies greatly, their diameter ranging from less than $5 \mathrm{~mm}$ to over $50 \mathrm{~mm}$ (Fig. 5), with a lack of intermediate-sized fragments. Fine-grained black-and-white-striped polyhalite is observed in primary halite (Fig. 5a), indicating that it was formed in a stable environment of low hydrodynamic conditions and high brine concentration. Relatively small polyhalite fragments occur mainly in the dark halite matrix (Fig. 5b), and the fragments were distributed in a radial or flower shape. Large polyhalite lumps or beds are broken and deformed, exhibiting plastic deformation in both the red and the black halite matrix (Fig. 5d). (2) Compared to the black halite matrix, the red halite matrix contains more polyhalite fragments. The fragments are well-sorted and rounded, especially those with a diameter of 5-10 mm (Fig. 5e). Large lumps or beds (or laminae) of highly crushed and deformed polyhalite fragments occur locally (Fig. 5f). The dark-red polyhalite-rich halite layer and pure red halite layer are interbedded, showing abrupt boundaries (Fig. 5g), exhibiting the same dip direction, and both retain their original sedimentary characteristics.

\subsection{Lithological characteristics of polyhalite}

One- to ten-mm-thick light and dark sedimentary/primary laminae are developed in the polyhalite (Fig. 5a), which however were disrupted by plastic deformation, and exhibit no directionality, i.e., they are not consistent with the orientation of the strata. Fine crystal powder polyhalite is grayish-black to reddish in color and is translucent, with a waxy luster and conchoidal fractures (Fig. 6). The crystals are short-cylindrical to longcolumnar or rod-shaped (Fig. 7b, c), Hypidiomorphicallotriomorphic crystals are observed (Fig. 7a), with common complex twin crystals and crystalline ridges, the length varying greatly (Fig. 8), from $5 \mu \mathrm{m}$ to more than $400 \mu \mathrm{m}$. Generally, in the center of an aggregate, the crystals are mostly subhedral, fine to medium in size $(0.05-0.5 \mathrm{~mm})$ and compact, and grow superimposed on each other. At the edges of an aggregate, the crystals are relatively large, mostly coarse subhedral to euhedral $(0.5-1 \mathrm{~mm})$, and are relatively poorly bound to other crystals. Compared with the central polyhalite crystals, the marginal ones were formed later, and were locally recrystallized as giant polyhalite crystals $(>1 \mathrm{~mm}$ ) (Fig. $8 \mathrm{c}, \mathrm{d})$, implying an un-restricted growth space. Thus, these crystals may have formed before halite or before halite consolidation. Under the microscope, polyhalite aggregates have the following features: (1) A mosaic structure, with very clear crystal boundaries (Fig. 8c); (2) directional distribution of polyhalite crystals, showing mylonite characteristics (Fig. 8d); (3) variable crystal size in the aggregates, showing no clear crystal boundaries and no obvious orientation (Fig. 8e), which points to reprecipitation; and (4) crenulations in some polyhalite aggregates, indicating two deformation stages (Fig. 8f).

\subsection{Paragenesis}

The polyhalite and other minerals show the following paragenesis: (1) Some medium- to large-sized polyhalite crystals (or crystal twins) are distributed independently as subhedral to anhedral inclusions (Fig. 9a) in the halite matrix, while some occur as polyhalite aggregates and also disperse in the halite matrix (Fig. 9b). The boundaries between polyhalite and halite crystals are clear without metasomatism (Fig. 9b, c). (2) Black organic matter exhibits a stratified distribution in polyhalite, similar to that in other sediments and evaporative materials, which may be influenced by seasonal changes and is responsible for forming bedding in polyhalite (Fig. 9b). (3) There are three kinds of contacts between polyhalite and anhydrite: (i) The boundary is clear and straight, with no visible evidence of metasomatism (Fig. 9d). (ii) Evidence of metasomatism is common, especially in the SEM data, and there are no clear boundaries between polyhalite and anhydrite (Fig. 9e). At the edge of the aggregates, anhydrite crystals with uneven contours are observed, which are relics of incomplete replacement by polyhalite (Fig. 9f; Peryt et al. 1998). (iii) In the aggregates, polyhalite has been replaced by and been surrounded by anhydrite (Fig. 9g, h). Gypsum can be formed during 

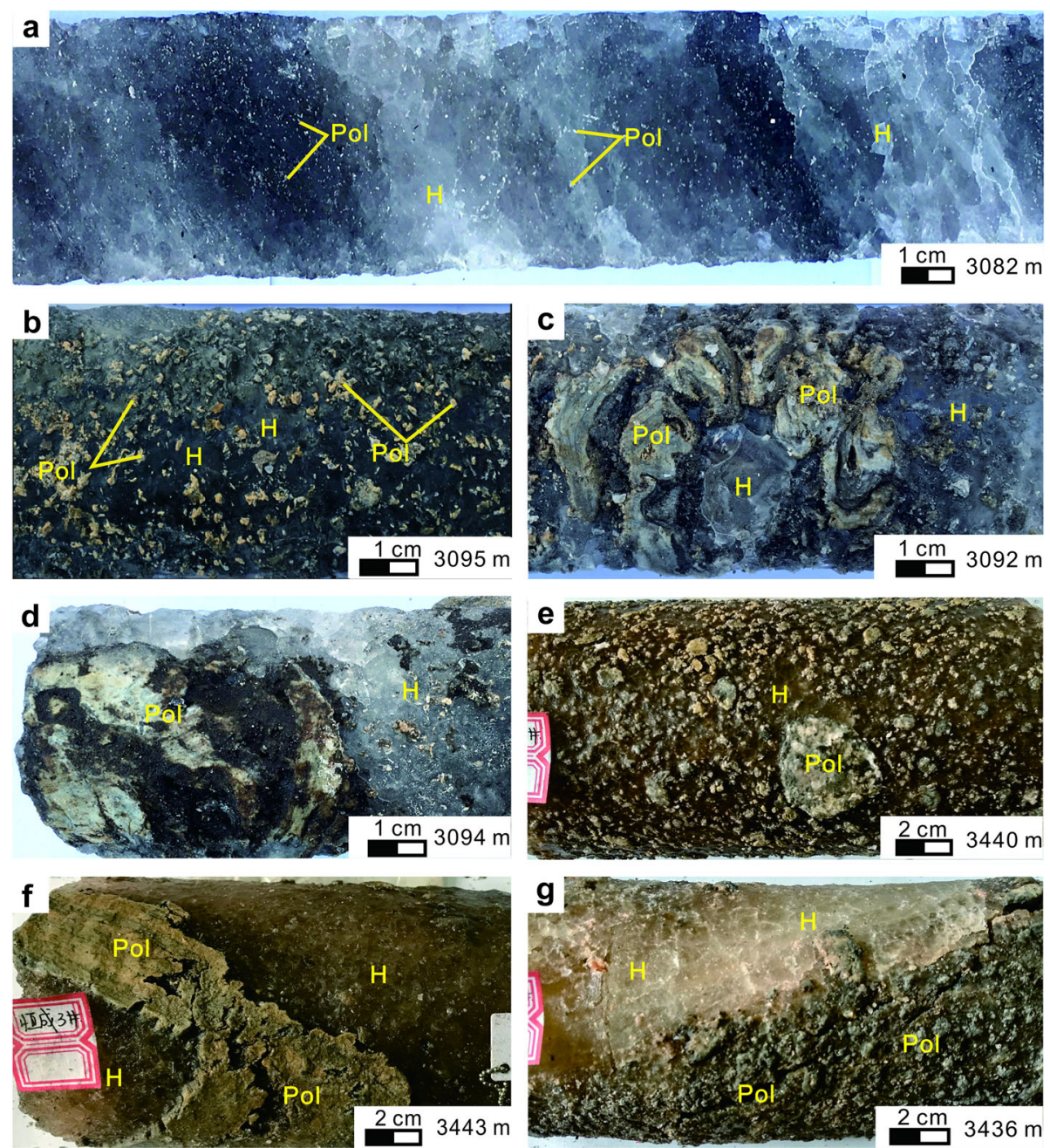

Fig. 5 Distribution characteristics of polyhalite in different kinds of halite matrix. a Fine-grained polyhalite distributed in the primary halite layers in black halite; b Fine-grained polyhalite distributed in black halite; c Banded polyhalite distributed in black halite; $\mathbf{d}$ A large polyhalite lump distributed in pure black halite; e Medium-grained polyhalite distributed in red halite; $\mathbf{f}$ A large polyhalite lump in red halite; $\mathbf{g}$ Thin polyhalite-rich layer interbedded with a halite layer. a-d Well ZK001; e-g Well HC3. H = Halite; Pol = Polyhalite

dissolution of polyhalite, which envelops remaining polyhalite, and prevents further dissolution. Therefore, the polyhalite occurring in gypsum (anhydrite) is difficult to exploit.

\section{Discussion}

The theoretical origin of polyhalite and previous research results suggest that metasomatic polyhalite forms in two ways: (1) it forms from $\mathrm{K}^{+}$- and $\mathrm{Mg}^{2+}$-rich brine reacting with calcium sulfate; or (2) it forms from $\mathrm{Ca}^{2+}$ and $\mathrm{SO}_{4}{ }^{2-}$-rich fluids reacting with salt minerals containing potassium and magnesium, such as sylvite or carnallite. Thus, metasomatic polyhalite is mainly associated with calcium-containing sulfate (such as anhydrite), sylvite, carnallite, etc. The deposition of polyhalite associated with halite should occur under the following conditions: During halite deposition, strong evaporation and concentration lead to gradual enrichment of $\mathrm{K}^{+}$and $\mathrm{Mg}^{2+}$ in the brine; at this point, a small amount of $\mathrm{Ca}^{2+}$ rich fluid flows into the concentrated brine and forms primary polyhalite (Zhao et al. 1987). This type of polyhalite often occurs as relatively thin, stable and extensive layers in the middle and upper parts of halite. The polyhalite is relatively pure and exhibits no metasomatism. It shows microstratification or rhythmic structure due to continuous evaporation and concentration of brine (Yuan 1974; Wang 1982; Zhao et al. 1987). In the NTPPO, the polyhalite occurs as clastics distributed in the halite layers, which does not conform to the typical characteristics of primary sedimentation or metasomatism mentioned above, but the laminated texture can be observed in these polyhalite fragments, implying this type of polyhalite used to be layered, and was broken by some geological process to form these clastics. 

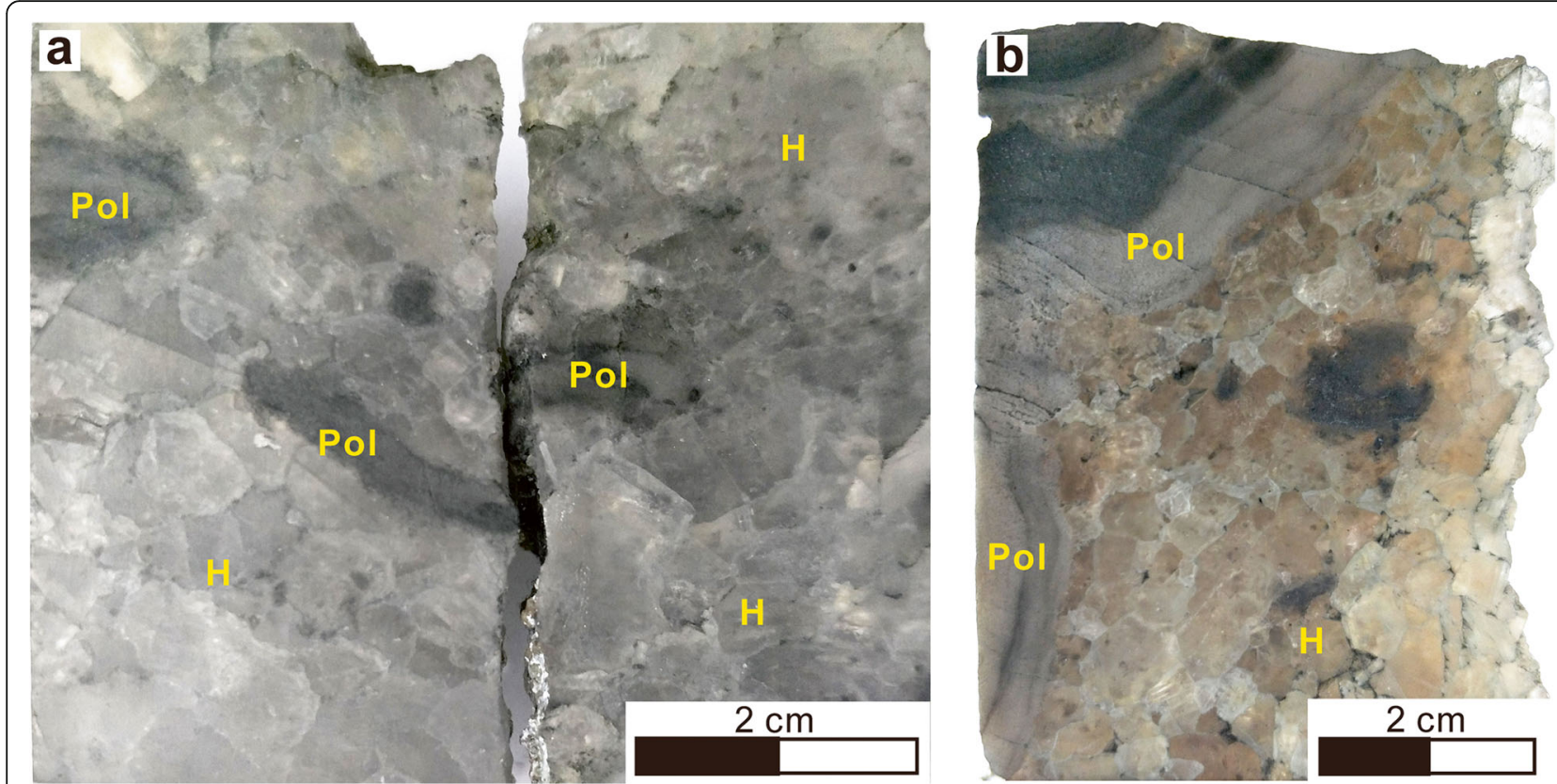

Fig. 6 Characteristics of polyhalite in polished core samples. a Polyhalite fragments in black halite of the Well ZK001. The polyhalite is grayishblack to reddish in color and is translucent, with a waxy luster. The crystal is fine-grained and exhibits conchoidal fractures. At $3083 \mathrm{~m}$ depth. $\mathbf{b} \mathrm{A}$ polyhalite fragment in red halite of the Well HC3, 1-10-mm-thick light and dark sedimentary/primary laminae are developed in the polyhalite, which were disrupted by plastic deformation and exhibit no directionality, that is, they are not consistent with the orientation of the strata, at 3445 m depth. $\mathrm{H}=$ Halite; $\mathrm{Pol}=$ Polyhalite

In addition, observations in modern sedimentary salt basins and experiments prove that metasomatic gypsum can form polyhalite (Holser 1966; Yuan 1974). The polyhalite in the Sichuan Basin, symbiotic with anhydrite, is often considered to have been formed by metasomatic anhydrite (e.g., Pan 1988; Li and Han 1987; Lin and Yin 1998), but in our samples, the polyhalite is distributed in halite layer instead of in anhydrite (or gypsum) layers. Obviously, the above-mentioned metasomatism cannot form such characteristic polyhalite. The polyhalite aggregates exhibit various textures, such as tuft-like, fibrous, radial, speckle, and petal-like, similar to the anhydritetype polyhalite in the Nongle region in the Sichuan Basin (Liao et al. 1984; Pan 1988), Q Depression in Hubei Province (Wang 1982), Lop Nur of Xinjiang Uygur Autonomous Region (Liu et al. 2008), Dawenkou Depression of the Bohai Bay Basin (Zhao et al. 1987), Kunteyi Salt Lake of the Qaidam Basin (Liu et al. 2015),
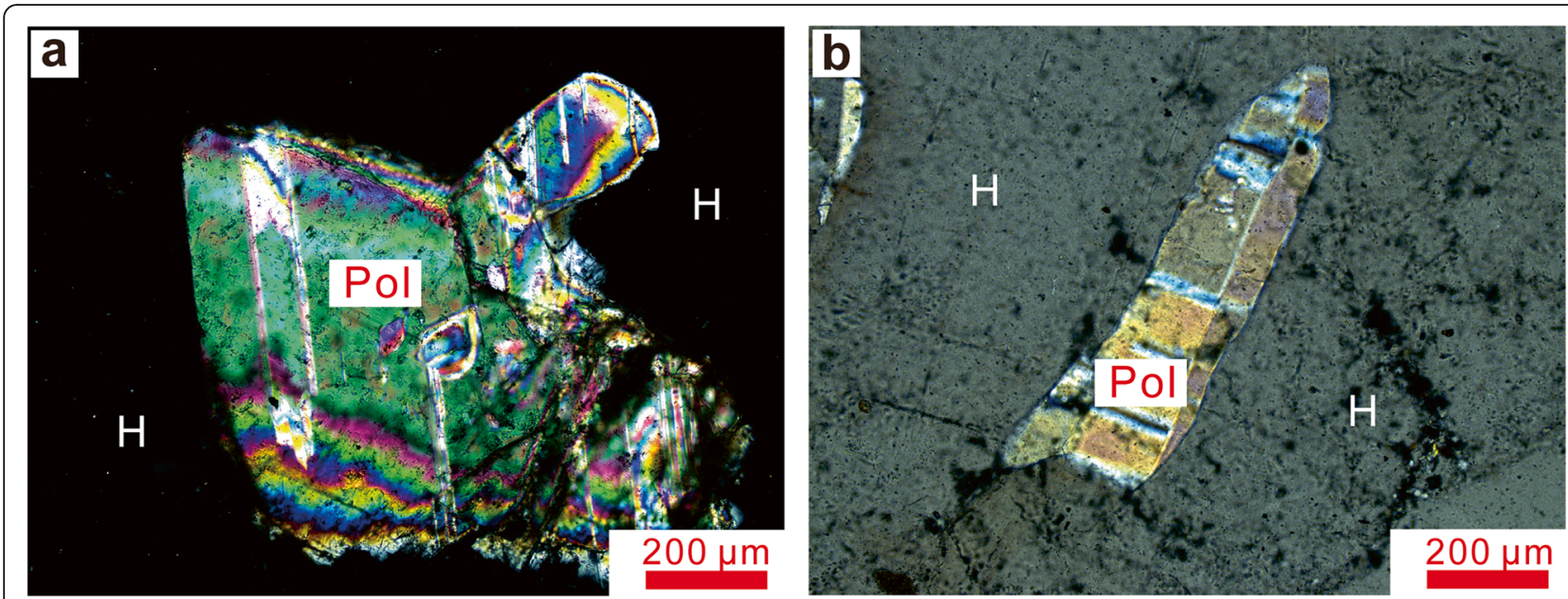

Fig. 7 Microscopic photograph of the polyhalite crystals under cross-polarized light (XPL). a A short-cylindrical polyhalite crystal from the Well ZK001, at 3085 m depth; b A long-columnar polyhalite crystal from the Well HC3, at 3444 m depth. H= Halite; Pol = Polyhalite 

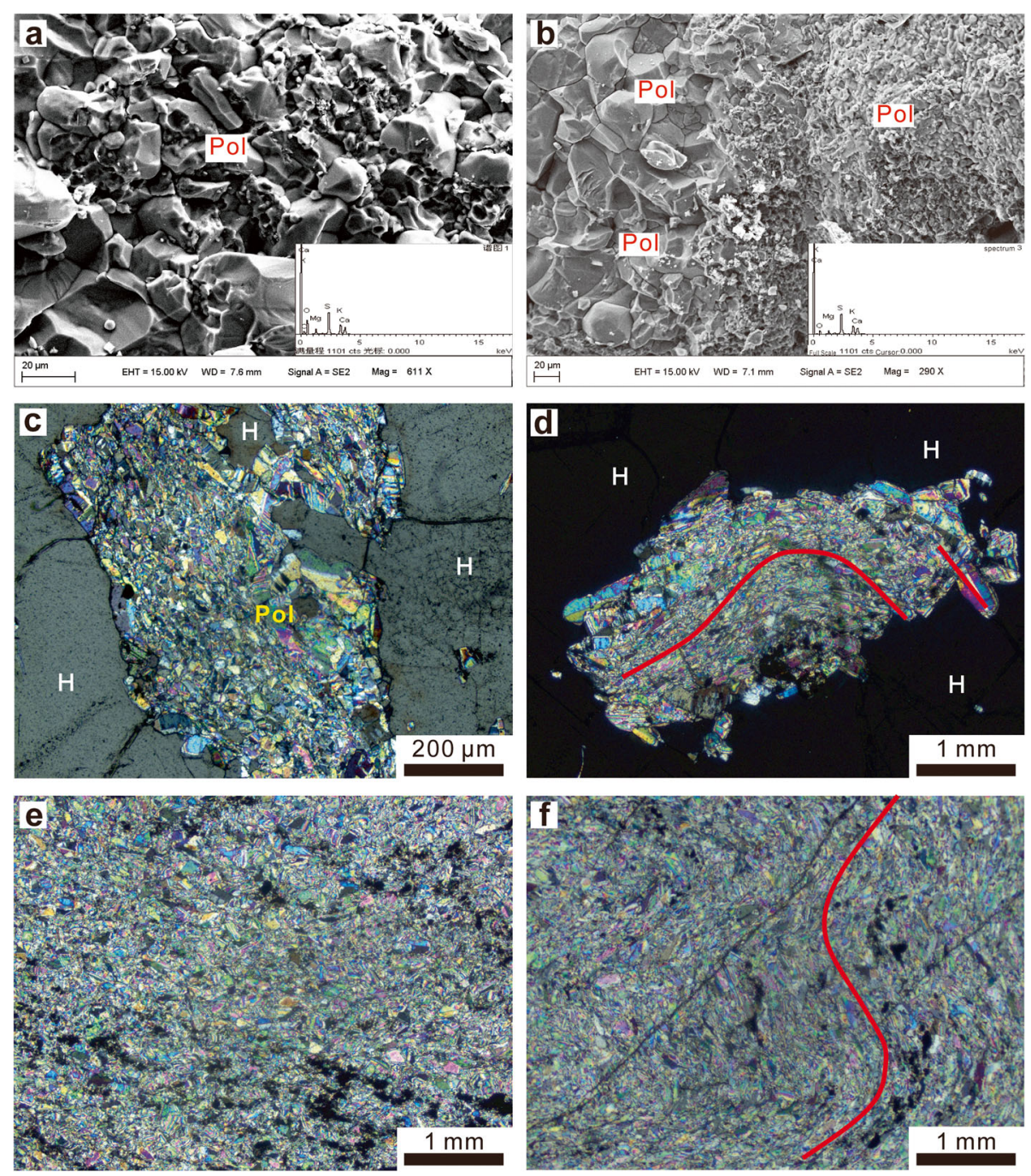

Fig. 8 Micrographic characteristics of the polyhalite aggregates. $\mathrm{H}=$ Halite; Pol=Polyhalite. a Subhedral granular texture of polyhalite. Sample from Well ZKO01 at $3086.8 \mathrm{~m}$ depth, SEM. b Polyhalite with different crystal sizes. Sample from Well ZK001 at $3089 \mathrm{~m}$ depth, SEM. c Mosaic polyhalite structure. Sample from Well HC3 at $3444 \mathrm{~m}$ depth, XPL. d Oriented polyhalite crystals showing mylonite characteristics. Sample from Well HC3 at 3439 m depth, XPL. e Polyhalite crystals with no clear boundaries and no obvious direction. Sample from Well HC3 at $3441.5 \mathrm{~m}$ depth, XPL. f Fine-grained polyhalite showing two different bending directions, indicating two deformation stages. Sample from Well HC3 at $3444 \mathrm{~m}$ depth, XPL

and Bieletan area of the Qarhan Salt Lake, Qinghai (Niu et al. 2015). The polyhalite structure in the NTPPO is simple and blocky. In summary, in terms of genesis of the deposit, the NTPPO is a new type of polyhalite, which is different from that described in previous researches.

The polyhalite fragments in the NTPPO shows a laminar structure, which indicates that the original polyhalite layer was crushed due to storm events during deposition, or due to tectonic compression during late diagenesis. Which is the main cause for the formation of NTPPO? The halite layers and thin anhydrite layers in the NTPPO retain their original sedimentary characteristics, whereas the laminar structure of the polyhalite fragment has been destroyed, implying that the formation of the original polyhalite is earlier than the deposition of halite and anhydrite layers. The crystals at the edges of the polyhalite aggregates formed earlier than the halite, which also reflects this. Thus, we believe that the polyhalite fragment in halite is allogenic. Polyhalite forms $\mathrm{K}_{2} \mathrm{SO}_{4}, \mathrm{MgSO}_{4}$ and $\mathrm{CaSO}_{4}$ during the dissolution process, $\mathrm{CaSO}_{4}$ precipitates to form gypsum and wrapped polyhalite so that polyhalite cannot dissolve continuously. This is also the reason why the polyhalite, symbiotic with anhydrite, cannot be exploited by solution mining (Zheng et al. 2018). In the sample, the polyhalite fragments were found to be replaced by anhydrite on the edge of the polyhalite fragments. This is evidence 

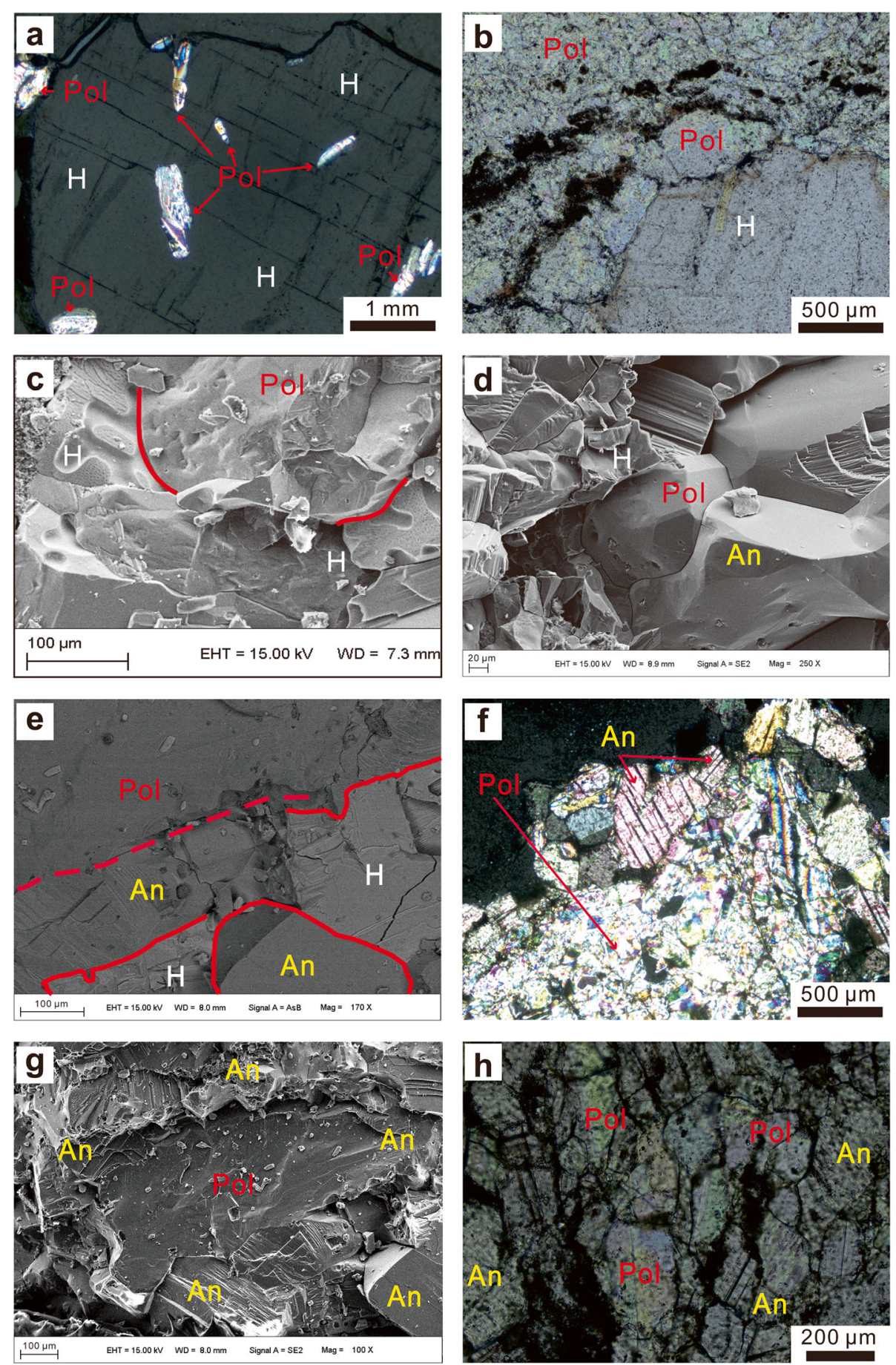

Fig. 9 The paragenesis between polyhalite and other minerals. An =Anhydrite; $\mathrm{H}=\mathrm{Halite}$; Pol = Polyhalite. a Medium- to large-sized subhedral to anhedral crystals (or crystal twins) dispersed in halite matrix as inclusions. At $3439 \mathrm{~m}$ depth in Well HC3, XPL. b Banded polyhalite containing organic matter distributed in the halite matrix. At $3441.5 \mathrm{~m}$ depth in Well HC3, XPL. c Halite squeezed by polyhalite, with clear and straight boundary (solid line). At $3086 \mathrm{~m}$ depth in the Well ZKO01, SEM. d Anhydrite and halite squeezed by polyhalite, with clear and straight boundaries. At $3100 \mathrm{~m}$ depth in Well ZK001, SEM. e No clear boundary (dashed line) between polyhalite and anhydrite, but very clear boundaries (solid lines) between other crystals. At $3088 \mathrm{~m}$ depth in Well ZK001, SEM. f Residual structure of anhydrite at the edges of a polyhalite aggregate. At $3100 \mathrm{~m}$ depth in Well ZK001, XPL. g Polyhalite encased in anhydrite, with no clear boundary. At $3089 \mathrm{~m}$ depth in Well ZK001, SEM. h Polyhalite replaced and encased by anhydrite. At $3100 \mathrm{~m}$ depth in Well ZKO01, XPL 
that the polyhalite fragments had been partially dissolved, in other words, polyhalite fragments were once carried by water with lower salinity. To sum up, combined with other characteristics of NTPPO, we imagine that it formed through the process illustrated in Fig. 10: During the Early Triassic, the Sichuan Basin was a harsh environment with an intense monsoon and high temperatures. The West Qinling Trough experienced strong storms, while the Pingjiang and Kaijiang uplifts increased the hydrodynamic conditions in the area, resulting in fragmentation of unconsolidated or weakly-consolidated gypsum (turning into anhydrite during complex diagenesis)-polyhalite layers on the gypsum flat or at the bottom of the salt basin. After these fragments had been carried into the salt basin by storm-induced currents (or had been re-deposited in situ), the gypsum in the fragments reacted with $\mathrm{K}$ - and $\mathrm{M}$-rich brines in the basin to continue to form polyhalite, which resulted in a complex metasomatism between polyhalite and gypsum/anhydrite, and increased the amount of polyhalite. The polyhalite content in the fragments is very high, usually more than $90 \%$, from which it is inferred that during diagenesis, the anhydrite/gypsum in the fragments continued to form polyhalite by reacting with $\mathrm{K}-\mathrm{Mg}$-rich brines.
The long-term existence of $\mathrm{K}-\mathrm{Mg}$-rich brines also led to the recrystallization of polyhalite, which resulted in larger, more complete and looser polyhalite crystals at the edge of the fragments. Finally, the polyhalite fragments were cemented by halite. When storms transported material to the salt basin, the relatively large plastic polyhalite fragments were deposited first, which then were fixed by pure halite particles that had already formed at the bottom of the basin. Due to salinity differences of water bodies and the gradual decrease of the kinetic energy of storms, fragments with better sorting and rounding were deposited rapidly after a certain transport distance. Then, fine-grained fragments and black organic matter entrained by storm backflows were deposited above the larger polyhalite fragments. Therefore, compared to nearshore areas, the polyhalite fragments show different sedimentary characteristics in the center of a salt basin where more stable conditions exist. It has not been verified whether the mylonitic features of polyhalite were caused by breaking of the plastic sedimentary layer. However, during late diagenesis, under intense tectonic activities, polyhalite fragments were compressed along with halite deformation, which could have produced the mylonitic features of polyhalite and the slight

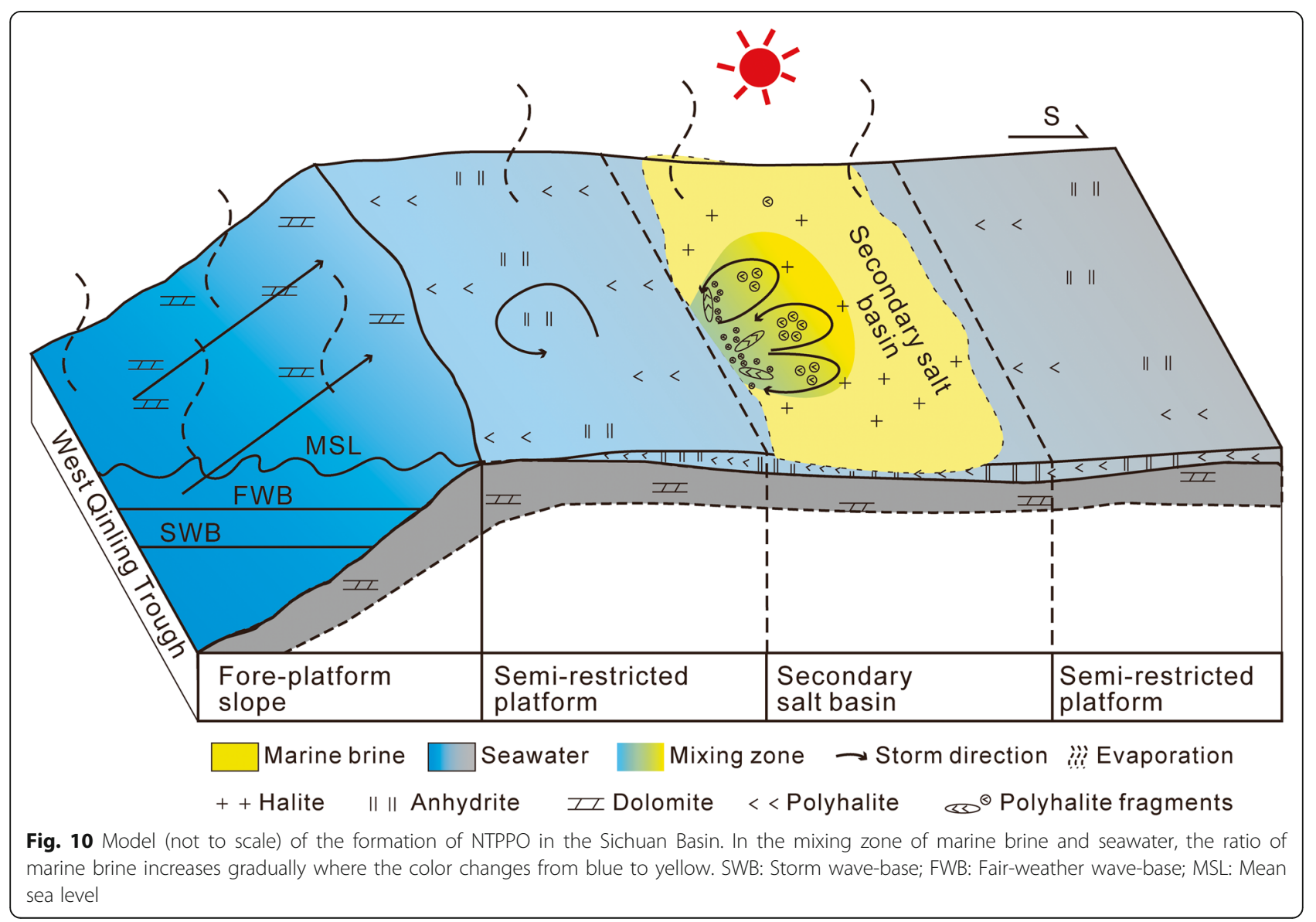


deformation of thin polyhalite and anhydrite layers in halite. In conclusion, according to the metallogenic model of the NTPPO, this kind of deposit may have developed at the edge of the Sichuan Basin (salt basin) during the Early Triassic period.

\section{Conclusions}

Recently, a kind of deep-buried polyhalite deposits with economic value was found in the Xuanhan area in the northeastern Sichuan Basin and is called a new type of polyhalite potassium ore (NTPPO). Fine- to mediumgrained polyhalite crystals, medium-to-large polyhalite aggregates, and polyhalite beds are distributed unevenly in the halite matrix. The main features and genesis are as follows:

The polyhalite aggregate has complex characteristics. It can be replaced by anhydrite; in adverse, it can be formed by metasomatism of the latter.

The sedimentary characteristics of polyhalite fragments differ according to environment. There are two kinds of polyhalite fragments in turbulent areas: coarsegrained and fine-grained. In tectonically stable areas, the polyhalite fragments are of better roundness than those in less stable areas.

The polyhalite fragments exhibit alternations of light and dark bands, which are interpreted to be primary. The primary polyhalite deposits were broken up, and developed as a layered polyhalite-anhydrite deposit.

The polyhalite fragments can be derived from the original polyhalite layer formed at or nearby the bottom of a salina. The highly concentrated $\mathrm{K}^{+}$- and $\mathrm{Mg}^{2+}$-rich brine enriched the polyhalite content in the fragments through metasomatism with gypsum and through recrystallization.

The NTPPO was the result of storm events and tectonic activities, with the former being the main agent.

\section{Abbreviations}

FWB: Fair-weather wave-base; H: Halite; MSL: Mean sea level; NTPPO: New type of polyhalite potassium ore; Pol: Polyhalite; SEM: Scanning electron microscopy; SWB: Storm wave-base; XPL: Cross-polarized light

\section{Acknowledgements}

The authors like to thank Dazhou Hengcheng Energy (Group) Limited Liability Company for providing the cores. WJS would like to thank the China Geological Survey and the SinoProbe for funding this research work.

\section{Authors' contributions}

WJS carried out mineral microfacies study and analysis, participated in field work and drafted the manuscript. Other authors participated in manuscript revision and drawing. All authors have read and approved the final manuscript.

\section{Funding}

This study was performed under the China Geological Survey (Grant no. DD20190172) and the SinoProbe (Grant no. 2017YFC0602806).

\section{Availability of data and materials}

All data are available from the authors. Material is available from the corresponding repositories, as stated in the material section.

\section{Competing interests}

The authors declare that they have no competing interests.

\section{Author details}

${ }^{1}$ Institute of Mineral Resources, Chinese Academy of Geosciences, Beijing 100037, China. ${ }^{2}$ Key Laboratory of Salt Lake Resources and Environment, Ministry of Natural Resources, Beijing 100037, China. ${ }^{3}$ Key Laboratory of Mineralization and Resource Evaluation, Ministry of Natural Resources, Beijing 100037, China. ${ }^{4}$ Xi'an Center of Mineral Resources Survey, China Geological Survey, Xi'an 710199, Shaanxi Province, China.

Received: 27 November 2019 Accepted: 14 January 2021

Published online: 01 February 2021

\section{References}

Algeo, T.J., Z.Q. Chen, M.L. Fraiser, and R.J. Twitchett. 2011. Terrestrial-marine teleconnections in the collapse and rebuilding of early Triassic marine ecosystems. Palaeogeography, Palaeoclimatology, Palaeoecology 308 (12): $1-11$

Alroy, J., M. Aberhan, D.J. Bottjer, M. Foote, F.T. Fürsich, P.J. Harries, A.J. Hendy, S.M. Holland, L.C. Ivany, W. Kiessling, M.A. Kosnik, C.R. Marshall, A. J. McGowan, A.I. Miller, T.D. Olszewski, M.E. Patzkowsky, S.E. Peters, L. Villier, P.J. Wagner, N. Bonuso, P.S. Borkow, B. Brenneis, M.E. Clapham, L. M. Fall, C.A. Ferguson, V.L. Hanson, A.Z. Krug, K.M. Layou, E.H. Leckey, S. Nürnberg, C.M. Powers, J.A. Sessa, C. Simpson, A. Tomasovych, and C.C. Visaggi. 2008. Phanerozoic trends in the global diversity of marine invertebrates. Science 321 (5885): 97-100.

An, F.L., Y.L. Zhang, and X. Guo. 2009. Tectonic evolution and accumulation pattern of Puguang structure of Huangjinkou tectonic zone in Sichuan Basin. Marine Geology Letters 25 (5): 25-29 (in Chinese with English abstract).

An, L.Y., H.A. Yin, M.L. Tang, and L.F. Hao. 2004. Mechanism and feasibility study of solution mining of polyhalite. Mining and Metallurgical Engineering 24 (3): 5-7 11 (in Chinese with English abstract).

Chen, A.Q., L.C. Wang, G.J. Ji, K. Cao, S.L. Xu, and W.B. Tang. 2015. Evaporitic environment and the concentration model of potash in the earlymiddle Triassic, northeastern Sichuan Basin. Acta Petrologica Sinica 31 (9): 2757-2769 (in Chinese with English abstract).

Chen, J.X. 1999. The fertilizer effect of polyhalite on red soil. Soils 31 (1): 33 3553 (in Chinese with English abstract).

Chen, L.Q., Z.G. Shen, F.H. Hou, and S.X. Fang. 2010. Formation environment of Triassic evaporate rock basin and dolostone reservoirs in the Sichuan Basin. Petroleum Geology and Experiment 32 (4): 334-340 346 (in Chinese with English abstract).

Ding, G.Y., W.M. Gao, S.Y. Huang, and Y.W. Wu. 1964. Color characteristics and geological significance of quaternary sediments in North China plain. Scientia Geologica Sinica 5 (2): 143-159 (in Chinese).

Erwin, D.H. 1994. The Permo-Triassic extinction. Nature 367: 231-236

Freyer, D., and W. Voigt. 2003. Crystallization and phase stability of $\mathrm{CaSO}_{4}$ and $\mathrm{CaSO}_{4}$-based salts. Monatshefte für Chemie 134: 693-719.

Han, W.T. S.Q. Gu, and K.Q. Cai. 1982. On the formative conditions of polyhalite in the six-component system $\mathrm{K}^{+}, \mathrm{Na}^{+}, \mathrm{Mg}^{2+}, \mathrm{Ca}^{2+} / \mathrm{Cl}^{-}, \mathrm{SO}_{4}{ }^{2}$ ${ }^{-}-\mathrm{H}_{2} \mathrm{O}$. Chinese Science Bulletin 27 (6): 362-365 (in Chinese with English abstract).

Holser, W.T. 1966. Diagenetic polyhalite in recent salt from Baja California. American Mineralogist 51: 99-109.

Huang, X.Z. 1996. The fist polyhalite deposit of China. Yunnan Geology 15 (1): 52-61 (in Chinese with English abstract).

Jiang, M., K.Y. Ma, P. Li, W.Z. Zhang, and C.L. Lin. 1987. A study on paleomagnetism and physical properties of Triassic potassium-bearing strata in eastern Sichuan basin. Geophysical and Geochemical Exploration 11 ((4): 266-274 (in Chinese with English abstract). 
Jin, F. 1989. Enlightenment to China from the exploitation and utilization of the resources of halite abroad. Chemical Mining Technology 3: 31-34 (in (hinese).

Li, S.J., R. Zhang, and Q.C. Wang. 2006. Implications of the color of sediments and clay minerals for tertiary climatic changes of Kuqa depression. Acta Sedimentologica Sinica 24 (4): 521-530 (in Chinese with English abstract).

Li, Y.W., and W.T. Han. 1987. An experimental study on the formative conditions of polyhalite in Triassic system in Sichuan Basin. Geoscience 1 (3-4): 400-411 (in Chinese).

Liao, L.Z., F.H. Huang, Q.C. Liu, and C.S. Hu. 1984. The characteristics and origin of polyhalite in gypsum-anhydrite deposits in Nongle area, eastern Sichuan. Journal of Mineralogy and Petrology 1: 94-100 (in (hinese).

Lin, Y.T., and S.M. Yin. 1998. Distribution, genesis and significance of shallow-seated polyhalite ore in Quxian, Sichuan. Acta Geologica Sichuan 18 (2): 121-125 (in Chinese with English abstract).

Liu, C.L., M.L. Wang, P.C. Jiao, W.D. Fan, Y.Z. Chen, Z.C. Yang, and J.G. Wang. 2008. Sedimentary characteristics and origin of polyhalite in Lop Nur salt Lake, Xinjiang. Mineral Deposits 27 (6): 705-713 (in Chinese with English abstract).

Liu, Z., D.L. Gao, B.K. Li, X.L. Yuan, M.X. Wang, and B.L. Li. 2015. Sedimentary characteristics and origin of polyhalite of Kunty salt lake mine in Qaidam Basin. Journal of Salt Lake Research 23 (1): 30-37 (in Chinese with English abstract).

Mundil, R., K.R. Ludwig, I. Metcalfe, and P.R. Renne. 2004. Age and timing of the Permian mass extinctions: U/Pb dating of closed-system zircons. Science 305 (5691): 1760-1763.

Niu, X., P.C. Jiao, Y.T. Cao, Y.J. Zhao, and B.S. Liu. 2015. The origin of polyhalite and its indicating significance for the potash formation in the Bieletan area of the Qarhan salt Lake, Qinghai. Acta Geologica Sinica 89 (11): 2087-2095 (in Chinese with English abstract).

Ogg, J.G., and F.M. Gradstein. 2008. The concise geologic time scale. Cambridge: Cambridge University Press.

Pan, Z.H. 1988. A preliminary study on the genesis of polyhalite of middle and lower Triassic in the Nongle area, Quxian County, Sichuan Province. China Nonmetallic Minerals Industry (1):6-10 (in Chinese).

Parrish, J.T. 1993. Climate of the supercontinent Pangea. The Journal of Geology 101 (2): 215-233.

Payne, J.L., D.J. Lehrmann, J.Y. Wei, and A.H. Knoll. 2006. The pattern and timing of biotic recovery from the end-Permian extinction on the great Bank of Guizhou, Guizhou Province, China. Palaios 21 (1): 63-85.

Peryt, T.M., C. Pierre, and S.P. Gryniv. 1998. Origin of polyhalite deposits in the Zechstein (upper Permian) Zdrada platform (northern Poland). Sedimentology 45 (3): 565-578.

Qian, L.J., Z.Q. Shi, Z.W. Li, and L.H. Ou. 2010. Fossil wood of the upper Triassic Xujiahe formation on the western margin of Sichuan Basin: Implication for palaeoclimate. Acta Sedimentologica Sinica 28 (2): 324330 (in Chinese with English abstract).

Raup, D.M. 1979. Size of the Permo-Triassic bottleneck and its evolutionary implications. Science 206 (4415): 217-218.

Retallack, G.J. 1995. Permian-Triassic life crisis on land. Science 267 (5194): $77-80$.

Stanley, S.M. 1988. Paleozoic mass extinctions: Shared patterns suggest global cooling as a common cause. American Journal of Science 288 (4): 334-352.

Sun, Y.D., M.M. Joachimski, P.B. Wignall, C.B. Yan, Y.L. Chen, H.S. Jiang, L.N. Wang, and X.L. Lai. 2012. Lethally hot temperatures during the early Triassic greenhouse. Science 338 (6105): 366-370.

Tang, D.Q., L.J. Wang, T. Zeng, and X.L. Feng. 2008. Tectonic evolvement function to oil and gas pool's reformation in Xuanhan-Daxian area, northeastern Sichuan Basin. Geoscience 22 (2): 230-238 (in Chinese with English abstract).

Wang, M.L. 1982. The geological significance of polyhalite in depression Q. Geological Review 28 (1): 28-37 (in Chinese with English abstract).

Wollmann, G. 2010. Crystallization Fields of Polyhalite and Its Heavy Metal Analogues [Ph.D. thesis]. Freiberg: University Bergakademie Freiberg.
Wollmann, G., D. Freyer, and W. Voigt. 2008. Polyhalite and its analogous triple salts. Monatshefte fuer Chemie 139: 739-745.

Wollmann, G., J. Seidel, and W. Voigt. 2009. Heat of solution of polyhalite and its analogues at $T=298.15 \mathrm{~K}$. The Journal of Chemical Thermodynamics 41 (4): 484-488.

$\mathrm{Xu}$, G.S., and Y.H. Zhao. 2003. Analysis on the forming mechanism of the carboniferous gas reservoirs in the Kaijiang paleohigh region of East Sichuan area. Petroleum Geology and Experiment 25 (2): 158-163 (in Chinese with English abstract).

Yin, H.F., and H.J. Song. 2013. Mass extinction and Pangea integration during the Paleozoic-Mesozoic transition. Scientia Sinica (Terrae) 43 (10): 1539-1552 (in Chinese).

Yuan, J.Q. 1974. Brief introduction of foreign polyhalite. Industrial Minerals and Processing 6: 47-58 (in Chinese).

Zhang, S.L., Z.X. LV, Y. Wen, and S.B. Liu. 2018. Origins and geochemistry of dolomites and their dissolution in the middle Triassic Leikoupo formation, western Sichuan Basin, China. Minerals 8 (7): 2-16.

Zhao, D.J., W.T. Han, K.Q. Cai, and J.H. Gao. 1987. The study of polyhalite genesis and its significance of potash-finding in Dawenkou depression, Shandong Province. Earth Science - Journal of Wuhan College of Geology 12 (4): 349-356 (in Chinese with English abstract).

Zhao, Y.J., C.L. Liu, D.X. Gong, J.Y. Zhou, T. Ding, M.Q. Wang, and L.C. Wang 2015. The Luzhou-Kaijiang paleouplift control on the formation environments of Triassic salt and potassium of deposits in eastern Sichuan. Acta Geologica Sinica 89 (11): 1983-1989 (in Chinese with English abstract).

Zheng, M.P., H.R. Yuan, Y.S. Zhang, X.F. Liu, W.X. Chen, and J.S. Li. 2010 Regional distribution and prospects of potash in China. Acta Geologica Sinica 84 (11): 1523-1553 (in Chinese with English abstract).

Zheng, M.P., Y.S. Zhang, W.J. Shang, E.Y. Xing, J.A. Zhong, B.L. Gui, and Y. Peng. 2018. Discovery of a new type of polyhalite potassium ore in Puguang region, northeastern Sichuan. Geology in China 45 (5): 1074 1075 (in Chinese).

Zhou, L., F. Li, D.F. He, Y. Hu, Y. Wu, and P. Lu. 2013. Structure and evolution characteristics analysis of Triassic in northern Sichuan Basin. Chinese Journal of Geology 48 (1): 71-92 (in Chinese with English abstract).

Zhou, W., Q. Wang, Q.Y. Zhao, L. Zhou, and W.Q. Shen. 1990. Color variation of surface sediment in south Bohai Sea. Marine Sciences 3: 31-35 (in Chinese with English abstract).

Zhu, Z.W., T.Y. Hao, and H.S. Zhao. 1988. Paleomagnetic study on the tectonic motion of Pan-xi block and adjacent area during YinzhiYanshan period. Acta Geophysica Sinica 31 (4): 420-431 (in Chinese with English abstract).

\section{Publisher's Note}

Springer Nature remains neutral with regard to jurisdictional claims in published maps and institutional affiliations.

\section{Submit your manuscript to a SpringerOpen ${ }^{\circ}$ journal and benefit from:}

- Convenient online submission

- Rigorous peer review

- Open access: articles freely available online

- High visibility within the field

- Retaining the copyright to your article

Submit your next manuscript at $\boldsymbol{\nabla}$ springeropen.com 